\title{
A thalidomide-hydroxyurea hybrid increases HbF production in sickle cell mice and reduces the release of proinflammatory cytokines in cultured monocytes
}

\author{
Carolina Lanaro ${ }^{\mathrm{a}}$, Carla F. Franco-Penteado ${ }^{\mathrm{a}}$, Fabio H. Silva ${ }^{\mathrm{a}}$, Kleber Y. Fertrin ${ }^{\mathrm{a}, \mathrm{b}}$, \\ Jean Leandro dos Santos ${ }^{c}$, Marlene Wade ${ }^{d}$, Shobha Yerigenahally ${ }^{\mathrm{d}}$, Thais R. de Melo ${ }^{\mathrm{c}}$, \\ Chung Man Chin ${ }^{c}$, Abdullah Kutlar ${ }^{\mathrm{e}}$, Steffen E. Meiler ${ }^{\mathrm{d}}$, and Fernando Ferreira Costa ${ }^{\mathrm{a}}$ \\ ${ }^{a}$ Hematology and Hemotherapy Center, University of Campinas-UNICAMP, Campinas, Brazil; ${ }^{\mathrm{b}}$ Department of Clinical Pathology, School of Medicine, \\ University of Campinas-UNICAMP, Campinas, Brazil; ' São Paulo State University (UNESP), School of Pharmaceutical Science, Araraquara, Brazil; \\ ${ }^{\mathrm{d}}$ Department of Anesthesiology and Perioperative Medicine, Augusta University, Augusta, GA; ${ }^{\mathrm{e}}$ Department of Medicine, Medical College of Georgia, \\ Augusta University, Augusta, GA
}

(Received 18 August 2017; revised 25 October 2017; accepted 27 October 2017)

\begin{abstract}
Fetal hemoglobin (HbF) induction by hydroxyurea (HU) therapy is associated with decreased morbidity and mortality in sickle cell anemia (SCA) patients, but not all patients respond to or tolerate HU. This provides a rationale for developing novel HbF inducers to treat SCA. Thalidomide analogs have the ability to induce $\mathrm{HbF}$ production while inhibiting the release of tumor necrosis factor-alpha. Molecular hybridization of $\mathrm{HU}$ and thalidomide was used to synthesize 3- (1,3-dioxoisoindolin-2-yl) benzyl nitrate (compound 4C). In this study, we show that compound $4 \mathrm{C}$ increases $\mathrm{HbF}$ production in a transgenic SCA mouse model and reduces the production of pro-inflammatory cytokines by SCA mouse monocytes cultured ex vivo. Therefore, compound $4 \mathrm{C}$ is a novel drug designed to treat SCA with a unique combination of $\mathrm{HbF}$-inducing and anti-inflammatory properties. (C) 2018 ISEH - Society for Hematology and Stem Cells. Published by Elsevier Inc. All rights reserved.
\end{abstract}

Fetal hemoglobin $\left(\mathrm{HbF}, \alpha_{2} \gamma_{2}\right)$ is the major hemoglobin in fetal life. The switch from $\gamma$-globin to $\beta$-globin occurs shortly after birth, when $\mathrm{HbF}$ is replaced by $\mathrm{HbA}\left(\alpha_{2} \beta_{2}\right)$, the main hemoglobin in adulthood. Patients with sickle cell anemia (SCA) display higher levels of $\mathrm{HbF}$ than healthy individuals, whose $\mathrm{HbF}$ concentration is less than $1 \%$ of total hemoglobin. $\mathrm{HbF}$ does not interact with $\mathrm{HbS}$ and limits polymerization of $\mathrm{HbS}$ within red blood cells (RBCs) [1], which provides a sound rationale for the development of $\mathrm{HbF}$ inducers as treatment options for SCA [2].

Hydroxyurea (HU), a known $\mathrm{HbF}$ inducer and ribonucleotide reductase inhibitor, is a drug approved by the U.S. Food and Drug Administration (FDA) for the treatment of SCA. Beneficial effects of $\mathrm{HU}$ appear to be associated with its nitric

Offprint requests to: Fernando Ferreira Costa, MD, PhD, Rua Carlos Chagas, 480, Cidade Universitária, 13083-878, Campinas, SP, Brazil; E-mail: ferreira@unicamp.br oxide (NO)-donating property, and more importantly, with the induction of $\mathrm{HbF}$ production through NO-dependent activation of soluble guanylyl cyclase in erythroid cells [3,4]. In SCA patients, an increase in HbF levels by HU therapy is associated with decreased mortality and a reduced incidence of clinical complications such as the frequency of acute painful episodes and acute chest syndrome [5]. Unfortunately, some patients do not respond to or are unable to tolerate HU [4]. In light of these findings, it has been proposed that thalidomide and its analogs, lenalidomide and pomalidomide, can emerge as a promising novel class of drugs for the treatment of SCA through their combined ability to reduce inflammation and to induce $\mathrm{HbF}$ production. The mechanism through which thalidomide increases $\mathrm{HbF}$ involves p38 mitogen-activated protein kinase activation and $\mathrm{H} 4$ histone acetylation [6]. In addition, these drugs also can inhibit the release of tumor necrosis factor-alpha (TNF- $\alpha$ ) and others molecules involved in the inflammatory process [7-10]. 
Using a molecular modification approach, our group has previously described 3-(1,3-dioxoisoindolin-2-yl) benzyl nitrate (compound 4C), a novel candidate drug. It was synthesized through molecular hybridization of $\mathrm{HU}$ and thalidomide to obtain both NO donor and analgesic properties [10]. A recent study showed that priapism, a known complication of SCA, was reversed by compound $4 \mathrm{C}$ in transgenic SCA mice and combined endothelial NO synthase and neuronal NO synthase double gene-deficient mice [11]. In this study, we show that compound $4 \mathrm{C}$ increases $\mathrm{HbF}$ production in a transgenic SCA mouse model and reduces the production of proinflammatory cytokines by SCA mouse monocytes ex vivo.

\section{Methods}

\section{Animals and treatment}

Knockout-transgenic SCA mice were bred at Augusta University according to institutional guidelines [12]. Animals were housed in temperature-controlled facilities on a 12-hour light/dark cycle with ad libitum food and water access. Six-week-old male SCA mice were treated with compound $4 \mathrm{C}(300 \mu \mathrm{mol} / \mathrm{kg} / \mathrm{d})$ or its vehicle $(0.1 \%$ dimethylsulfoxide) daily (Monday through Friday) for 8 weeks via intraperitoneal injection. All animal procedures were approved by Augusta University's Animal Care and Use Committee (permit number: BR10-07-349).

\section{Hematological parameters}

Whole blood was collected by intracardiac puncture from ketamine/ xylazine-anesthetized mice in vacutainer EDTA tubes (BD Biosciences, Franklin Lakes, NJ, USA). Blood count was performed with a CBC-Diff Veterinary Hematology System (Heska Corporation, Loveland, CO, USA). Reticulocyte counts were determined by supravital staining with methylene blue.

\section{HbF measurement}

$\mathrm{HbF}$ was measured by analytic high-performance liquid chromatography using a weak cation-exchange column SynChropak CM300 (Eprogen) on the Waters Empower 32 high-performance liquid chromatography system (Millipore).

\section{Interleukin (IL)-1 $\beta, I L-6$, and KC measurement in monocyte cultures from SCA mice}

Cells were purified of peripheral blood using Ficoll (GE Healthcare, Pittsburgh, PA, USA) gradient separation. Mononuclear cells were placed in plastic dishes with Dulbecco's modified Eagle's medium (Life Technologies, Carlsbad, CA, USA) with $10 \%$ calf bovine serum (ATCC, Manassas, VA, USA) and incubated for 2 hours in humidified air $\left(5 \% \mathrm{CO}_{2}\right.$ at $\left.37^{\circ} \mathrm{C}\right)$. Purity of monocytes was $>90 \%$ as determined by May-Giemsa staining (Fisher Scientific, Pittsburgh, PA, USA). Compound 4C was added to the monocyte cultures at different concentrations (100 or $300 \mu \mathrm{mol} / \mathrm{L}$ ) for 30 minutes before stimulation with lipopolysaccharide (LPS; $1 \mu \mathrm{g} / \mathrm{mL}$; SigmaAldrich, St. Louis, MO, USA). After 20 hours of incubation, supernatants were collected and stored at $-80^{\circ} \mathrm{C}$ until analysis. IL$1 \beta$, IL-6, and KC (also known as cytokine CXCL1, a murine analog of human IL-8) were determined using commercially available ELISA kits (R\&D Systems, Minneapolis, MN, USA).

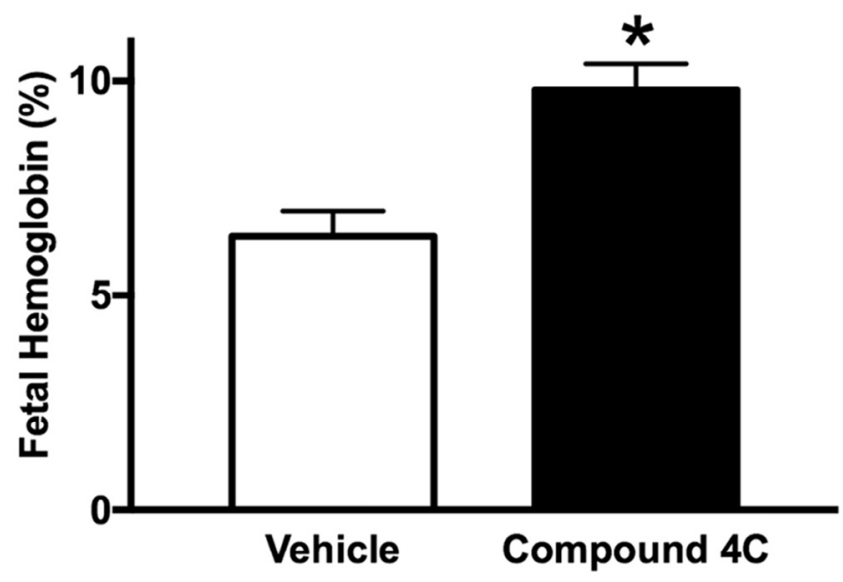

Figure 1. HbF protein levels from SCA mice treated with or without compound $4 \mathrm{C}(300 \mu \mathrm{mol} / \mathrm{kg} / \mathrm{d}$ for 8 weeks). Data are shown as the mean $\pm \mathrm{SEM}$ for seven to 10 mice in each group. ${ }^{*} p<0.05$ compared with the vehicletreated group.

\section{Results}

Compound 4C increases $\mathrm{HbF}$ protein levels in SCA mice. Eight weeks of treatment with compound $4 \mathrm{C}$ increased the protein levels of $\mathrm{HbF}$ by approximately $53 \%$ in SCA mice compared with mice treated with vehicle $(p<0.05$; Fig. 1$)$. This increase in $\mathrm{HbF}$ was accompanied by only a slight decrease in hemoglobin, RBC, and white blood cell (WBC) counts in the experimental group (Table 1).

Compound $4 \mathrm{C}$ reduces the production of IL- $1 \beta$, IL- 6 , and $\mathrm{KC}$ in supernatants of monocyte cultures from SCA mice. Pretreatment of SCA mouse monocyte cultures with compound $4 \mathrm{C}$ at concentrations of 100 and $300 \mu \mathrm{mol} / \mathrm{L}$ caused a significant reduction of IL-1 3 (57\% and $93 \%$, respectively; $p<0.05$; Fig. 2A), IL-6 (70\% and 97\%, respectively; $p<0.05$; Fig. 2B), and $\mathrm{KC}$ at the $300 \mu \mathrm{mol} / \mathrm{L}$ concentration (89\%; $p<0.05$; Fig. 2C) compared with vehicle-treated cultures. The magnitude of the anti-inflammatory properties of compound $\mathrm{C}$ at the higher concentration equaled or exceeded dexamethasone's suppressive effect on LPS-induced cytokine production (Fig. 2). Incubation with $\mathrm{HU}$ at similar

Table 1. Hematological parameters of SCA mice treated with compound $4 \mathrm{C}$

\begin{tabular}{lrr}
\hline Parameter & \multicolumn{1}{c}{ Vehicle } & Compound 4C \\
\hline RBCs $\left(\times 10^{6} / \mu \mathrm{L}\right)$ & $4.7 \pm 0.4$ & $3.9 \pm 0.3$ \\
Hb $(\mathrm{g} / \mathrm{dL})$ & $7.2 \pm 0.4$ & $6.3 \pm 0.4$ \\
HCT $(\%)$ & $21.4 \pm 1.4$ & $16.6 \pm 1.3$ \\
Reticulocytes $(\%)$ & $42.6 \pm 4.1$ & $39.6 \pm 5.2$ \\
WBCs $\left(\times 10^{6} / \mu \mathrm{L}\right)$ & $11.4 \pm 1.0$ & $10.4 \pm 0.8$ \\
MCV $(\mathrm{fL})$ & $45.9 \pm 1.6$ & $42.8 \pm 2.0$ \\
MCH $(\mathrm{pg})$ & $15.6 \pm 0.5$ & $17 \pm 1.6$ \\
\hline
\end{tabular}

Data are shown as the mean \pm SEM of five to 10 mice in each group $(p>0.05$ for all parameters).

$\mathrm{HCT}=$ Hematocrit $\mathrm{MCH}=$ mean corpuscular hemoglobin; $\mathrm{MCV}=$ mean corpuscular volume. 
A
Compound 4C
Wydroxyurea
IIIII Dexamethasone

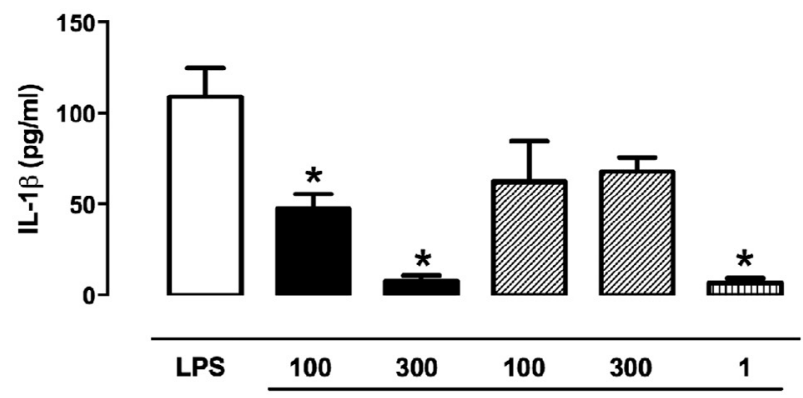

B

$\mu \mathbf{M}$

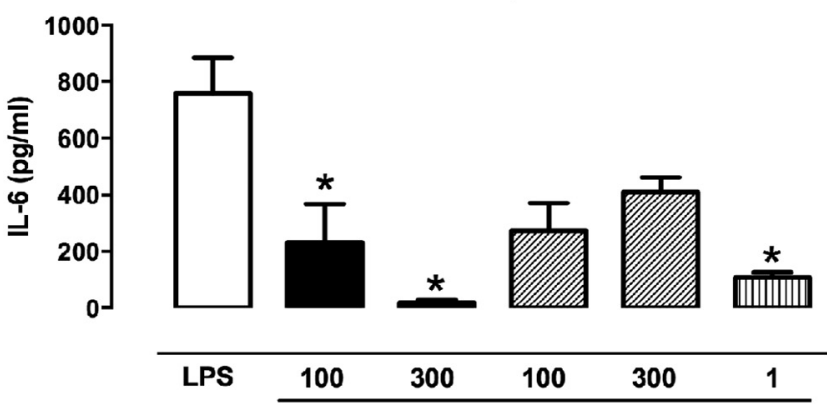

C

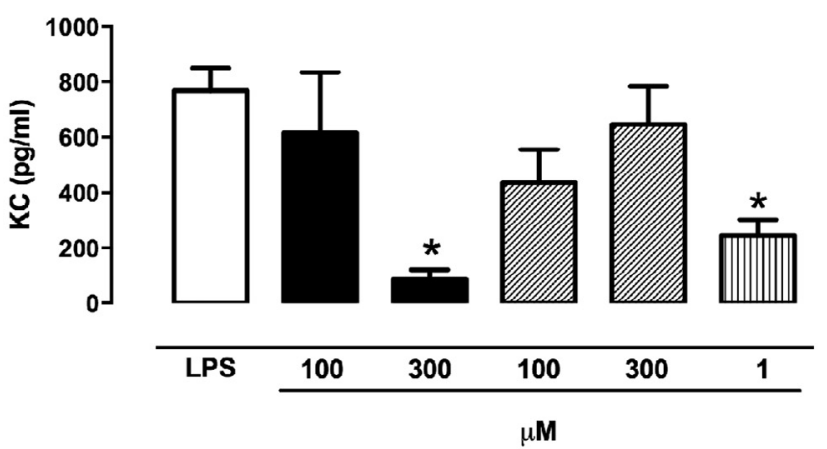

Figure 2. (A) IL-1 $\beta$, (B) IL-6, and (C) KC levels in LPS-stimulated SCA monocyte cultures in the presence of compound $4 \mathrm{C}(100$ or $300 \mu \mathrm{mol} / \mathrm{L})$, $\mathrm{HU}(100$ or $300 \mu \mathrm{mol} / \mathrm{L})$, or dexamethasone $(1 \mu \mathrm{mol} / \mathrm{L})$ as a positive control of anti-inflammatory drug. Data are shown as the mean \pm SEM of three to six mice in each group. ${ }^{*} p<0.05$ compared with the vehicle-treated group.

concentrations ( 100 or $300 \mu \mathrm{mol} / \mathrm{L}$ ) had no significant effect on the production of IL-1 $\beta$, IL-6, or KC (Fig. 2).

\section{Discussion}

Advances in our understanding of the pathophysiology of SCA have highlighted the importance of $\mathrm{HbF}$ in modulating the severity of the disease and increased awareness of the significant role of inflammation in the sickle vaso-occlusive process [13]. Compound 4C emerges as a novel drug: designed to treat SCA, it has the capacity to address both pathophysiological aspects of the disease as an $\mathrm{HbF}$ inducer with anti-inflammatory properties that combine the molecular structures of $\mathrm{HU}$ and thalidomide [10].

The HbF-inducing effect of compound $4 \mathrm{C}$ is similar to what our group has observed in transgenic SCA mice treated with $\mathrm{HU}$ and the thalidomide analog pomalidomide in a previous study [8]. This further supports the contribution of the pharmacophoric group of thalidomide in compound $4 \mathrm{C}$ to the induction of $\mathrm{HbF}$ and suggests that it may be as effective as $\mathrm{HU}$ in augmenting $\mathrm{HbF}$. In the future, we believe that compound $4 \mathrm{C}$ may become an alternative for SCA patients who are unresponsive to or unable to tolerate HU.

The exact mechanisms behind the HbF-inducing effects of compound $4 \mathrm{C}$ remain to be determined. Progress in understanding the mechanism of action of HU has identified that NO-donating compounds seem to increase $\gamma$-globin mRNA transcription and $\mathrm{HbF}$ expression in erythroid cells [3], which could justify this effect through the NO-donating group in compound $4 \mathrm{C}$. In addition, the pharmacophoric group of the thalidomide molecule may behave in a manner similar to pomalidomide, which has been demonstrated to induce $\mathrm{HbF}$ production by reducing the levels of key transcriptional repressors of $\gamma$-globin gene expression in erythroblasts, such as BCL11A, SOX6, GATA1, KLF1, and LSD1 [9]. Our data showed a slight decrease in Hb levels and RBC and WBC counts after treatment with compound $4 \mathrm{C}$, but a possible myelosuppressive effect was not expected, because this new hybrid does not have the pharmacophoric group from HU responsible for the inhibition of ribonucleotide reductase. The effect may nonetheless be caused by this new molecule, but more studies are needed to confirm.

In addition, compound $4 \mathrm{C}$ displays anti-inflammatory properties that may prove useful in the treatment of SCA. Previous studies have shown that thalidomide can decrease IL-6 levels in volunteers with experimental endotoxemia [14], as well as IL- $1 \beta$ production in whole blood cell cultures stimulated with LPS [15]. Regarding chemotaxis, a phthalimide analog coupled to a nitrate subunit reduced $\mathrm{KC}$ production induced by carrageenan in the paws of mice [16]. Chronic inflammation in SCA patients has been characterized by elevated plasma levels of TNF- $\alpha$ and IL-8 [17], increased IL- $1 \beta$ production by peripheral blood mononuclear cells from SCA patients [18], and increased circulating IL-6 levels in SCA vaso-occlusive crisis [19]. Furthermore, there is evidence that Cxcl1/KC is a key inflammatory mediator of vaso-occlusion in an SCA murine model of hemolytic transfusion reaction [20]. Our results expand our previously published observation that compound $4 \mathrm{C}$ is able to inhibit TNF- $\alpha$ production in LPS-stimulated monocytes from SCA mice [10], whereas HU lacks the ability to change IL-1 $\beta$, IL-6, and KC production in murine monocyte cultures. This compound can reduce chemokine production, a possible advantage compared with lenalidomide and pomalidomide, which have been shown not to change the production of chemokine IL-8 [21]. Therefore, the anti-inflammatory properties of compound $4 \mathrm{C}$ can 
be attributed to its pharmacophoric group from the thalidomide molecule and may be useful against the chronic inflammatory state in SCA patients. In fact, previous studies have reported that $\mathrm{HU}$ might induce the gene expression and synthesis of proinflammatory cytokines [22-24].

This study is limited by the use of ex vivo measurements of cytokines to document the anti-inflammatory properties instead of measuring circulating cytokines in the same murine model. There is still no method available to measure circulating levels of compound $4 \mathrm{C}$ to allow the study of drug pharmacokinetics. Therefore, we cannot determine the concentrations of compound $4 \mathrm{C}$ achieved, nor can we exclude the possibility that ideal $\mathrm{HbF}$-inducing and antiinflammatory properties may not be reached at the same concentrations of compound 4C. Nevertheless, our data will be helpful in the design of further in vivo investigations aiming at obtaining circulating concentrations of compound $4 \mathrm{C}$ with an anti-inflammatory effect that can be as potent as dexamethasone.

\section{Conclusions}

In summary, our study shows that 8 weeks of treatment with compound $4 \mathrm{C}$ increased $\mathrm{HbF}$ production in SCA mice. Moreover, compound $4 \mathrm{C}$ also decreased the IL- $1 \beta$, IL- 6 , and KC production in LPS-stimulated monocytes from this model of SCA. Compound $4 \mathrm{C}$ is a novel drug designed to treat SCA with a unique combination of HbF-inducing and antiinflammatory properties.

\section{Acknowledgments}

This work was supported by grant 2008/57441-0 from the São Paulo Research Foundation (FAPESP) and grant 558531/ 2008-3 from the National Council for Scientific and Technological Development (CNPq).

\section{References}

1. Akinsheye I, Alsultan A, Solovieff N, et al. Fetal hemoglobin in sickle cell anemia. Blood. 2011;118:19-27.

2. Humphries C. Drug development: a complicated path. Nature. 2014;515:S4-S5.

3. Cokic VP, Smith RD, Beleslin-Cokic BB, et al. Hydroxyurea induces fetal hemoglobin by the nitric oxide-dependent activation of soluble guanylyl cyclase. J Clin Invest. 2003;111:231-239.

4. Steinberg MH, Lu ZH, Barton FB, Terrin ML, Charache S, Dover GJ. Fetal hemoglobin in sickle cell anemia: determinants of response to hydroxyurea. Multicenter Study of Hydroxyurea. Blood. 1997;89:10781088.

5. Charache S, Terrin ML, Moore RD, et al. Effect of hydroxyurea on the frequency of painful crises in sickle cell anemia. N Engl J Med. 1995;332:1317-1322.

6. Aerbajinai W, Zhu J, Gao Z, Chin K, Rodgers GP. Thalidomide induces $\gamma$-globin gene expression through increased reactive oxygen speciesmediated p38 MAPK signaling and histone H4 acetylation in adult erythropoiesis. Blood. 2007;110:2864-2871.
7. Moutouh-de Parseval LA, Verhelle D, Glezer E, et al. Pomalidomide and lenalidomide regulate erythropoiesis and fetal hemoglobin production in human CD34+ cells. J Clin Invest. 2008;118:248-258.

8. Meiler SE, Wade M, Kutlar F, et al. Pomalidomide augments fetal hemoglobin production without the myelosuppressive effects of hydroxyurea in transgenic sickle cell mice. Blood. 2011;118:11091112.

9. Dulmovits BM, Appiah-Kubi AO, Papoin J, et al. Pomalidomide reverses $\gamma$-globin silencing through the transcriptional reprogramming of adult hematopoietic progenitors. Blood. 2016;127:1481-1492.

10. dos Santos JL, Lanaro C, Lima LM, et al. Design, synthesis, and pharmacological evaluation of novel hybrid compounds to treat sickle cell disease symptoms. J Med Chem. 2011;54:5811-5819.

11. Silva FH, Karakus S, Musicki B, et al. Beneficial effect of the nitric oxide donor compound 3-(1,3-dioxoisoindolin-2-yl)benzyl nitrate on dysregulated phosphodiesterase 5, NADPH oxidase and nitrosative stress in the sickle cell mouse penis: implication for priapism treatment. J Pharmacol Exp Ther. 2016;359:230-237.

12. Ryan TM, Ciavatta DJ, Townes TM. Knockout-transgenic mouse model of sickle cell disease. Science. 1997;278:873-876.

13. Manwani D, Frenette PS. Vaso-occlusion in sickle cell disease: pathophysiology and novel targeted therapies. Blood. 2013;122:38923898.

14. Shannon E, Noveck R, Sandoval F, Kamath B, Kearney M. Thalidomide suppressed interleukin-6 but not tumor necrosis factor-alpha in volunteers with experimental endotoxemia. Transl Res. 2007;150:275-280.

15. Shannon E, Noveck R, Sandoval F, Kamath B. Thalidomide suppressed IL-1beta while enhancing TNF-alpha and IL-10, when cells in whole blood were stimulated with lipopolysaccharide. Immunopharmacol Immunotoxicol. 2008;30:447-457.

16. Godin AM, Araújo DP, Menezes RR, et al. Activities of 2-phthalimidethanol and 2-phthalimidethyl nitrate, phthalimide analogs devoid of the glutarimide moiety, in experimental models of inflammatory pain and edema. Pharmacol Biochem Behav. 2014;122:291-298.

17. Lanaro C, Franco-Penteado CF, Albuqueque DM, Saad STO, Conran N, Costa FF. Altered levels of cytokines and inflammatory mediators in plasma and leukocytes of sickle cell anemia patients and effects of hydroxyurea therapy. J Leukoc Biol. 2009;85:235-242.

18. Pitanga TN, Oliveira RR, Zanette DL, et al. Sickle red cells as danger signals on proinflammatory gene expression, leukotriene B4 and interleukin-1 beta production in peripheral blood mononuclear cell. Cytokine. 2016;83:75-84.

19. Sarray S, Saleh LR, Lisa Saldanha F, Al-Habboubi HH, Mahdi N, Almawi WY. Serum IL-6, IL-10, and TNF $\alpha$ levels in pediatric sickle cell disease patients during vasoocclusive crisis and steady state condition. Cytokine. 2015;72:43-47.

20. Jang JE, Hod EA, Spitalnik SL, Frenette PS. CXCL1 and its receptor, CXCR2, mediate murine sickle cell vaso-occlusion during hemolytic transfusion reactions. J Clin Invest. 2011;121:1397-1401.

21. Lopez-Millan B, Diaz de la Guardia RD, Roca-Ho H, et al. Therapeutic effect of the immunomodulatory drug lenalidomide, but not pomalidomide, in experimental models of rheumatoid arthritis and inflammatory bowel disease. Exp Mol Med. 2017;49:e290.

22. Navarra P, Grohmann U, Nocentini G, et al. Hydroxyurea induces the gene expression and synthesis of proinflammatory cytokines in vivo. J Pharmacol Exp Ther. 1997;280:477-482.

23. Tavakkoli F, Nahavandi M, Wyche MQ, Perlin E. Plasma levels of TNF-alpha in sickle cell patients receiving hydroxyurea. Hematology. 2004;9:61-64

24. Laurance S, Pellay FX, Dossou-Yovo OP, et al. Hydroxycarbamide stimulates the production of proinflammatory cytokines by endothelial cells: relevance to sickle cell disease. Pharmacogenet Genomics. 2010;20:257-268. 